\title{
Artigo
}

REsumo
A imagem do recém-nascido
outrora visto como um ser
passivo passa a ser
substituída pela imagem de
um bebê ativo, dotado de
capacidades inatas que se
manifestam desde suas
primeiras interações com o
mundo. Essa nova
compreensão do bebê nos
convida a abordar um tempo
primitivo do psiquismo e da
formação do inconsciente.
Este trabalho deixa de lado a
idéia de um inconsciente
primitivo para falar da
existência de um núcleo
narcísico primário, conceito
winnicottiano que oferece um
novo paradigma que
corresponde à idéia desse
bebê participativo frente ao
processo da subjetivação.
Descritores: bebê,
intersubjetividade,
subjetivação, agressividade,
criatividade

\section{O PAPEL DO BEBÊ NO PROCESSO DE ACESSO À SUBJETIVAÇÃO}

\author{
Camila Saboia
}

(

omo poderemos abordar a participação do bebê na dinâmica de acesso ao campo da subjetivação? Em outras palavras, por qual via poderemos constatar o fato de que o bebê não ocupa mais o lugar de um simples nourrison ${ }^{1}$; aquele centrado apenas na atividade de se alimentar, exercendo um mero papel de receptor do ambiente?

Essas questões estão sendo cada vez mais propostas pelos clínicos da primeira infância, uma vez constatado que os estudos e as novas pesquisas têm revelado que o bebê é dotado de capacidades interativas que lhe propiciam condições de exercer um papel ativo desde suas primeiras interações com o mundo.

Essa nova posição do bebê ativo induz-nos a reelaborar certos conceitos abordados pela psicanálise clássica, principalmente no que diz respeito à

Psicanalista, doutoranda na Université Paris 7 - Denis Diderot, França. Pesquisadora do Projeto PILE -

Programme International pour le langage de l'enfant

(Hospital Necker, Paris). 
problemática de ontogênese humana, abordada pela metapsicologia, segundo uma lógica na qual predomina a idéia do intrapsíquico sobre o interpessoal. Nesse contexto, considera-se que o processo de construção da subjetivação estaria associado ao desenvolvimento de estados dentro de uma lógica da existência de estruturas bem definidas e descritíveis.

Essa tendência que vem se destacando expressa traços de herança das idéias iniciais sobre a sexualidade apresentadas por Freud em Trois essais sur la théorie sexuelle (1905/1987), segundo as quais a fonte da pulsão sexual teria sua origem no próprio organismo da criança; origem que dá a essa pulsão o atributo de ser auto-erótica, endógena e do tipo não-objetal. Partindo dessa perspectiva, Freud sustenta a hipótese de que a sexualidade seria vivida de forma espontânea, fato que nos leva a pensar que a construção de uma cena de sedução não seria determinante para o despertar da sexualidade na criança.

No entanto, se retomarmos o texto sobre o narcisismo, observamos que Freud (1914/2005) apresenta-nos a idéia de que para que ego seja formado é fundamental a existência de um objeto externo. Embora pouco desenvolvida na teoria freudiana, uma vez que ela tem como elemento central a figura do pai, a idéia da existência desse objeto pode validar a idéia de que os cuidados maternos foram desde sempre vistos como fundamentais para a inauguração da vida psíquica. Contudo, a referência à importância do papel da mãe parece não impedir Freud de sustentar a idéia da existência da sexualidade endógena, na medida em que a função do outro ganha o estatuto de um facilitador da diferenciação da energia sexual (libido) da energia de autoconservação.

Conseqüentemente, temos a idéia da existência de um bebê com pouca participação nesse momento primordial da constituição da vida psíquica; o que nos leva a pensar na imagem de um corpo que estaria completamente fechado em si, abrindo-se apenas num segundo momento, frente à presença do objeto externo.

Se retomarmos a idéia de que o recalque, nachdrangen, é da ordem de um tempo aprés-coup, dado o fato da existência de um recalque originário, uverdrangung, como não pensar que o bebê, desde o momento inicial de vida, não traria consigo algo de uma vida psíquica, mesmo que primitiva? E mais. Que elementos constituiriam esse momento da formação do recalque primário? Seria talvez apenas uma influência do pai da horda primária, Urvater, como nos propõe Freud em Totem et Tabou (1912/1993)?

Laplanche (1984) retoma esse tema no momento em que se indaga se a origem da pulsão estaria associada à ordem do biológico ou à ordem da interatividade? Dessa maneira, ele vai concei- 
tuar a hipótese de que a fonte originária da pulsão não se localizaria no organismo do bebê, e a pulsão sexual não teria como "brotar" espontaneamente do organismo, a não ser através da existência de uma mãe sedutora. Como mãe sedutora, Laplanche descreve a imagem de uma mãe provida de um inconsciente, diferentemente daquela apresentada por Freud, que a toma mais como um objeto real.

Assim, essa mãe laplanchiana seria portadora de um seio erógeno e erótico, o que implicaria o fato de que no momento em que ela oferece o seio ao seu bebê ela, concomitantemente, transmitelhe toda uma carga de imagens relacionadas ao seu próprio inconsciente. Nesse momento assistimos à instauração de uma sexualidade originária, provida pelo jogo de sedução estabelecido pela mãe. É apoiando-se nesse conceito que Laplanche (1985) vai criticar toda a posição de Freud, enfatizando o fato de que ele não pôde distinguir plenamente as contingências das manobras sexuais, ditas perversas, da situação da sedução originária. Ao contrário, ele teria facilmente desistido de sua "neurótica", em vez de dedicar-se ao aprofundamento das questões referentes às tramas da sedução.

Laplanche (1987), ainda acrescenta a idéia de que a pulsão sexual não surgiria no simples ato de desprendimento da pulsão de autoconservação, num movimento de satisfação das necessidades. $\mathrm{O}$ autor reformula o conceito de anaclisia, Anlehnung, de Freud, ao enfatizar que a sedução seria o único objeto fonte da pulsão, substituindo o esquema anaclítico pela sedução generalizada, a séduction originaire, e afirma ainda que não haveria diferenciação do tempo entre recalque primário e secundário; ambos se constituiriam concomitantemente. Essa constatação sugere que desde os tempos primordiais da vida já haveria sexualidade; portanto, os tempos do auto-erotismo e do narcisismo coincidiriam. Essa nova perspectiva permite-nos compreender esse primeiro tempo da constituição do aparelho psíquico não recorrendo às hipóteses de existência de um inconsciente concebido por influência de ordem genética ou filogenética.

Dessa maneira, observamos que os pressupostos teóricos laplanchianos oferecem-nos novas formas de abordar a clínica da primeira infância, na medida em que fazem referência a um momento anterior à instauração da linguagem. É abordando esse tempo primitivo da vida psíquica que podemos contribuir para a construção de novos procedimentos do trabalho de investigação precoce dos transtornos globais do desenvolvimento manifestos na primeira infância, tais como o autismo e a psicose infantil.

Embora considere que a posição de Laplanche (1985) propõe-nos novos meios de pensar esse tempo pré-simbólico, no qual 
se inclui a clínica com bebês, entendo que ele ainda segue o pensamento da tendência da psicanálise clássica e estruturalista. Isso porque o foco principal gira ainda em torno dessa mãe dotada da responsabilidade de dar forma a essa vida psíquica do bebê em que ela seria a protagonista do encontro entre eles.

Como então pensar sobre o fato de que haveria partes do corpo do bebê que seriam mais investidas do que outras? Será mesmo que o bebê posiciona-se passivamente frente ao mundo, talvez um depositário dos fantasmas maternais? E mais, será que esse processo da subjetivação se daria apenas pela via materna? Por que não direcionar nosso olhar também para o bebê a fim de decodificar suas mensagens, transmitidas por meio dos movimentos do seu corpo, do seu olhar, da ritmicidade e mesmo da tonalidade da freqüência de sua vOZ?

Considerando todas as questões levantadas a respeito da posição do bebê, podemos ainda nos perguntar de que maneira compreenderíamos que em alguns casos - verificados em diagnósticos precoces - o autismo se desencadeie mesmo na presença de uma mãe dita suficientemente boa? Por qual motivo se daria esse fechamento psíquico prematuro do bebê que já demonstra, desde suas primeiras interações com o mundo, uma enorme dificuldade de interagir com o ambiente? Enfim, por que esse movimento de recusa do bebê a atender o chamado dessa mãe que o convo$\mathrm{ca}$, numa tentativa de construir um encontro em que seja possível a subjetivação?
Considero que é pertinente recorrer aqui à obra winnicottiana, principalmente, pelo fato de Winnicott (1969a) oferecer uma nova via para compreender esse tempo primitivo do psiquismo. $\mathrm{O}$ autor não considera que haveria a fundação de um inconsciente primitivo, mas sim a existência de um núcleo narcísico primário, nomeado verdadeiro self, e que se constituiria por intermédio de um jogo de economia de força com o próprio ambiente.

Winnicott (1988) ainda nos diz que o estado de ser como um estado que antecede ao eu sou seria a primeira manifestação da natureza humana; algo que precederia as referências das marcas instauradas a partir do jogo de interação entre mãe e bebê. É possível pensar que esse estado poderia estar correlacionado ao que é potencialmente herdado, de forma que apenas na presença de um ambiente suficientemente bom o bebê poderia dar forma à constituição do seu self, acedendo ao campo da subjetivação. Prevaleceria, então, a idéia de que a criança se constituiria subjetivamente a partir da interação, do encontro com o outro.

É nesse sentido que Winnicott indica que entre o estado de não-ser e o estado de ser haveria um estado de transição, um campo intermediário; uma área que seria caracterizada pelas marcas desse encontro inicial entre mãe e bebê; um momento em que supomos que ambos contribuiriam de forma ativa na dinâmica do processo de maturação afetiva do bebê. Inferimos, então, que é pelo viés da correlação entre a noção do estado de ser e do estado de não- ser, entendido 

mos formas de refletir sobre esse tempo relativo ao tempo do pré-simbólico.

Quando Winnicott (1972) fala de agressividade, é interessante ter em mente o fato de ele lançar mão do termo agression e não agressivity. Se formos buscar o termo na origem da língua inglesa, constataremos que o termo agression nos diz: 1 - unprovoked attack, 2 - the act of beginning a quarrel or war, 3 - behaviour intend to injure another person or animal, ao passo que agressivity ou agressiveness transmite a idéia de: 1 - offensive, 2 - disposed to attack others.

Assim, partindo das definições acima mencionadas, percebemos que o termo escolhido por Winnicott, agression, ilustra bem a imagem de um bebê ativo e participativo. Aquele, que tenta "devorar" o ambiente com imensa voracidade (craving), lançando-se na difícil tarefa de adaptar-se ao mundo; condição primordial para que ele se constitua como sujeito.

Conseqüentemente, a agressividade ganha um estatuto de atividade, de maneira que passa a ser associada mais à idéia de força, de vida, do que de pulsão de morte, como nos propõe Freud (1920/ 1981). Desse modo, Winnicott $(1972,1969 b)$ vai enfatizar que a agressividade seria vista como uma forma de potencial existente desde os momentos precoces do recém-nascido, antes mesmo do estado de integração do self. Assim, ela estaria associada à idéia dos movimentos de motricidade, presentes desde a vida intra-uterina, de maneira que haveria, portanto, uma diferença entre a agressividade originária (primary agression) e a agressividade secundária. Esta última estaria associada às expressões de sentimentos de sadismo e de raiva; relacionadas a um estado emocional mais elaborado.

$\mathrm{O}$ autor acrescenta ainda que a fantasia se manifesta no indivíduo no momento em que a agressividade torna-se presente. Nesse sentido, os elementos associados a essa agressividade originária é que proporcionariam a destruição dos objetos por parte do bebê e, conseqüentemente, o surgimento do princípio da realidade.

Por esse viés, poderíamos aqui supor que seria essa agressividade a mola propulsora da origem da pulsão; dado o fato de que Winnicott afirma que a falta dos elementos constitutivos da agressividade, no momento do processo de maturação psicoafetiva, poderia comprometer a capacidade da criança de amar e de estabelecer relações com o objeto. Winnicott acrescenta ainda que esses elementos referentes à agressividade poderiam sofrer níveis de variação tanto no nível quantitativo como qualitativo. Numa variação que estaria associada diretamente às condições de adaptação do recém-nascido ao ambiente suficientemente bom.

Assim, partindo desse pressuposto teórico, podemos repensar a prática-clínica no campo da investigação precoce das psicopa- 
tologias graves na infância, uma vez que sabemos que algumas patologias de ordem neurológica e genética podem agir diretamente no nível desses elementos constitutivos da agressividade. Desse modo, seria válido então ressaltar a maneira como poderíamos detectar esses sinais precoces manifestados na primeira infância.

Considerar essa questão da agressividade é indiretamente remeter ao conceito de criatividade, levantado por Winnicott (1975), já que ambos os conceitos estariam intrinsecamente associados. É graças à presença da agressividade que o infans pode destruir o objeto. Esse objeto destruído, sobrevivendo a essa destruição, passa a ser visto como qualquer coisa referente à realidade compartilhada, constituindo, assim, a realidade externa.

Winnicott enfatiza que esse movimento de distinguir o que é de fora e o que é de dentro só poderia acontecer graças à capacidade de criar e de imaginar do bebê. Mesmo que para isso seja necessário, primeiramente, que a mãe apresente o objeto ao bebê. Dessa maneira, dizemos que o movimento que o bebê faz para alcançar (reach out) o objeto apresentado pela mãe configuraria a constatação da importância da agressividade como elemento fundador e primordial, responsável por levar o bebê a lançarse na direção da exploração do mundo. Assim, inferimos que seria essa relação com o objeto que determinaria a forma como o bebê vai aceder ao campo da subjetivação.

Winnicott (1975) enfatiza ainda que antes de estar apto a fazer uso do objeto (object-usage) de maneira rica e criativa, o bebê primeiramente aprende a relacionar-se com o objeto (object-relating). Esse modo mais primitivo de maturação da criança estaria associado ao primeiro espaço potencial, nomeado playground, que compreende então um jogo primitivo, estabelecido entre mãe-bebê. Assim, somente após a existência desse espaço de troca é que o espaço transicional pode revelar-se uma prova de que o bebê agora estaria apto a circular pelo campo do simbólico, o que engloba a sua capacidade de brincar (playing).

Apoiando-nos nessa perspectiva devemos mencionar as pesquisas atuais no campo da clínica do bebê e da primeira infância. Isto porque, a meu ver, elas nos remetem às questões referentes a esse espaço de transição; isto é, ao estado de continuar sendo (going on being) que levanto neste trabalho. Refiro-me aos estudos sobre a conceitualização da intersubjetividade.

A intersubjetividade é uma noção recente, e vem ganhando cada vez mais espaço na clínica precoce, na medida em que ela nos oferece novas ferramentas para pensar sobre a nosologia das psicopatologias. O próprio termo "inter" sugere a idéia de relação e de comunicação, enquanto "subjetividade" oferece-nos a imagem daquilo que pertence ao próprio sujeito, ao intuitivo, e àquilo que lhe é mais próprio e íntimo.

Podemos ainda dizer que esse conceito nos diz da noção de um processo progressivo, que justifica falarmos em acesso à intersubjetividade. A palavra acesso oferece-nos uma nova idéia de algo que não é previa- 
mente dado. Nesse contexto, é necessário repensar a noção de estruturalismo, no sentido de tomá-lo pelo viés da compreensão do termo processo (estruturalismo do movimento) ao invés de estado (referente às formas fixas); questão que novamente coloca em voga o persistente debate entre os que aderem à corrente teórica que sustenta uma lógica do interpessoal e aqueles que seguem o pensamento do intrapsíquico.

Bernard Golse (2006a, 2006b) diz-nos que a intersubjetividade consiste num processo de diferenciação extrapsíquica que corresponderia a um movimento gradual, por parte do bebê, de sair de um estado de simbiose original para um segundo estado, que lhe daria a consciência de separação, de reconhecer que dois não faz um. Esse movimento inscreve-se, então, na perspectiva de um processo dinâmico; o que significa levar em conta que o bebê poderia, por sua vez, participar de maneira ativa nesse processo. Tais pressupostos parecemme ir ao encontro da hipótese que levanto neste trabalho sobre a importância fundamental dos componentes $\mathrm{da}$ agressividade.

Assim, os estudos atuais revelam-nos que a criança, desde os estágios mais precoces da sua vida, já se comunica, e, portanto, já emite mensagens por meio de seu corpo. Nessas circunstâncias, devemos então sublinhar a importância da existência da agressividade versus criatividade, pois seria graças à existência desses elementos que o bebê, desde o início, lança-se no mundo, a fim de decodificar essas mensagens emitidas pela figura materna.
Devemos acentuar ainda que o ato de explorar engloba o fato de o bebê transformar as mensagens enviadas pelo ambiente. Desse modo, uma vez transformadas, elas serão emitidas com marcas próprias e genuínas do bebê, fazendo jus a todo seu potencial criativo.

Assim, importa levar em conta que nesse jogo inicial do playground estabelecido entre a dupla mãe e bebê, a criança expressa suas vivências nos níveis corporal, auditivo e sensitivo. Essas experiências, como constatamos, devem-se à presença desses elementos da agressividade originária; o que nos leva a pensar que um bebê com problemas de ordem neurológica poderia já, de antemão, apresentar variações na sua maneira de vivenciar e de expressar todas essas experiências do início de sua vida. No entanto, penso que isso não seria o fator principal para o desencadeamento de algumas patologias graves na infância.

Para concluir, convém atentar para não cairmos no lado extremo de um pensamento positivista e linear no qual se sustenta a imagem de que a presença de um bebê dito "passivo", necessariamente já significa uma criança com riscos autísticos. Esses tipos de diagnósticos ditos prematuros e lineares estão longe de corresponder à clinica da intervenção precoce, uma vez que essa clínica abrange a compreensão da complexidade de tudo que o bebê nos comunica, focalizando o trabalho da díade mãe-bebê no sentido de conhecer as particularidades desse momento único e primordial que ainda nos é tão desconhecido. 


\section{Abstract}

THE ROLE OF THE BABY IN THE PROCESS OF ACCESSES TO SUBJECTIVATION

The newly born considered as an passive being tends to be substituted by the image of an "active baby». This baby would be endowed with innate potentials expressed from the very first interactions with the environment, which invites us to consider what would be a primitive time of psychic life and the construction of the unconscious. This work nevertheless leaves aside the idea of an original unconscious, and refers to winicottian concepts like the «primary narcissisist core». This concept offers a new paradigm that goes along with the idea that the baby takes active part into the process of subjectivation.

Index terms: baby; intersubjectivity; subjectivation; agression; creativity

\section{RESUMEN}

\section{EL PAPEL DEL BÉBE EN LOS PROCESOS DE ACESSO A LA} SUBJECTIVACION

La imagen del recien nacido pasivo tiende a ser subsituida por la imagen de un bebé activo. Dicho bebé estaria dotado de capacidades innatas que se que manifestarian a partir de sus primeras interacciones con el mundo. Esta nueva concepción del bebé nos conduce a considerar un tiempo primitivo de la vida psíquica y la construcción del inconsciente. Este trabajo sin embargo deja a un lado la idea de un inconsciente originario, basandose en conceptos winicotianos del núcleo narcisico primario. Dicho concepto nos oferece un paradigma ligado a la idea de que el bébé forma parte activa en el proceso de subjectivacion.

Palabras clave: bebé; intersubjetivacion; subjetivation; agressividade; creatividad

\section{REFERÊNCIAS BIBLIOGRÁFICAS}

Abram, J. (2001). Le langage de Winnicott: Dictionnaire explicatif des termes winnicottiens (C. Athanassious, trad.). Paris: Popesco.

Athanassious, C. (2004). Le noyau narcissique primaire. Ses rapports avec le vrai self winnicottien. In Winnicott insolite. Paris : PUF.

Freud, S. (1981). Au-delà du principe de plaisir. In S. Freud, Essais de psychanalyse (J. Laplanche \& J. B. Pontalis, trad., pp. 43-114). (Trabalho original publicado em 1920)

(1987). La sexualité infantile. In S. Freud, Trois essais sur la théorie sexuelle. (J. Laplanche \& J-B. Pontalis, trad. pp. 94-140). Paris: Gallimard. (Trabalho original publicado em 1905)

(1993). Le retour infantile du totémisme. In S. Freud, Totem et tabou. (J. Laplanche \& J-B.Pontalis, trad., pp. 276-296). Paris : Gallimard. (Trabalho original publicado em 1912)

(2005). Pour introduire le narcissisme. In S. Freud, La vie sexuelle. (J.

Laplanche, D. Berger \& colaboradores, pp 82-105). Paris: PUF. (Trabalho original publicado em 1914)

Golse, B. (2006a). L'être bébé. Paris: PUF.

(2006b). L'intersubjectivité. Archives Carnetpsy. Texto recuperado em 20 jul. 2006: http://www.carnetpsy.com/Archives/Recherches/Items/ p41.htm. 


\section{Artigo}

Laplanche, J. (1984). La pulsion et son objet source : son destin dans le transfert . In J. Laplanche, La pulsion, pourquoi faire? (pp. 9-24). Paris: Association Psychanalytique de France.

(1985). Je ne crois plus à ma neurotica. In J. Laplanche, Fantasme originaire, fantasmes des origines, origines du fantasme (pp. 28-47). Paris: Hachette Littératures.

(1987). Vers la théorie de la séduction généralisée. In J. Laplanche, Nowveaux fondements pour la psychanalyse ( pp. 89-148). Paris: PUF.

Laplanche, J. \& Pontalis, J.-B.(1987). Vocabulaire de la psychanalyse. Paris: PUF.

Melmed-Posners, B., Wolfeglickman, R., Coyle-Taylor, E ., Canfield, J. \& Cye, F. (2004). Agressivité et créativité in Winnicott. In J. Bouhsira \& M.-C. Durieux (Orgs.), Winnicott insolite (pp.93-108). Paris: PUF.

Winnicott, D. (1962) Intégration du moi au cour du développement de l'enfant. In Processus de maturation chez l'enfant. (J. Kalmanovitch, trad.. Paris: Payot. (1969a). Le développement affectif primaire. In De la pédiatrique à la psychanalyse. (J. Kalmanovitch, trad., pp. 57-71). Paris: Payot.

(1969b). L'agressivité et ses rapports avec le développement affectif. In D. Winnicott, De la pédiatrique à la psychanalyse (J. Kalmanovitch, trad., pp. 150-168). Paris: Payot.

(1972). L'agressivité. In D. Winnicott, L'enfant et le monde extérieur. Le développement des relations (A. Stonck, trad., pp. 147-157). Paris: Payot.

(1975). Jeu et réalité : L'espace potentiel. (C. Monod \& J.-B Pontalis, trad.). Paris: Gallimard.

(1988). Agressivité, culpabilité et réparation. In D. Winnicott, Conversations ordinaries (B. Bost, trad., pp. 89-98). Paris: Gallimard.

(1988). La nature bumain. (B.Weil, trad.). Paris: Gallimard.

${ }^{1}$ Lactente.

camila_saboia@hotmail.com

Recebido em outubro/2006. Aceito em novembro/ 2006. 